Received: 18 June 2021 :: Accepted: 25 June 2021 :: Published: 30 June 2021

\title{
PENYULUHAN TEKNIK RELAKSASI OTOT PROGRESIF UNTUK MENURUNKAN KADAR GULA DARAH PADA PASIEN DIABETES MELLITUS TIPE 2 DI RUMAH SAKIT GRANDMED
}

\section{Sari Desi Esta Ulina Sitepu ${ }^{1 *}$, Tati Murni Karokaro², Pratiwi Christa Simarmata², Amriani Eva Perawati Silalahi ${ }^{2}$, Kardina Hayati ${ }^{3}$, Selamat Tuahta Sipayung ${ }^{1}$}

\author{
${ }^{1}$ Program Studi Keperawatan D3, Institut Kesehatan Medistra Lubuk Pakam \\ ${ }^{2}$ Program Studi Keperawatan S1, Institut Kesehatan Medistra Lubuk Pakam \\ ${ }^{3}$ Program Studi Pendidikan Profesi Ners, Institut Kesehatan Medistra Lubuk Pakam
JIn. Sudirman No.38 Lubuk Pakam, Kabupaten Deli Serdang, Sumatera Utara-Indonesia
*email korespondensi author : sitepudesisari@gmail.com

DOI $10.35451 / j p k . v 1 i 1.760$

\begin{abstract}
Abstrak
Prevalensi diabetes yang terjadi pada tahun 2015 sebesar 9,3\% dan kemungkinan akan terus bertambah kasusnya setiap tahun. Diabetes melitus tipe 2 disebabkan oleh resistensi terhadap insulin, yaitu glukosa yang gagal masuk ke dalam tubuh, umumnya menimpa masyarakat yang telah berusia di atas 30 tahun. Relaksasi otot progresif merupakan salah satu terapi yang dapat menurunkan kadar gula. Tujuan dari kegiatan pengabdian terhadap masyarakat ini ialah agar mengetahui manfaat dari teknik relaksasi otot progresif terhadap penurunan kadar gula dalam darah pada pasein DM tipe 2 di Rumah Sakit Grandmed Lubuk Pakam. Metode yang digunakan dalam pengabdian masyarakat ini adalah adalah ceramah dan aplikasi, dengan cara memberikan penyuluhan kepada pasien DM tipe 2 dan melakukan observasi setelah selesai melakukan penyuluhan. Penerapan teknik relaksasi otot dilakukan terhadap 10 orang penderita penyakit DM tipe 2. Prosedur pengabdian masyarakat dimulai dari penjelasan tentang teknik dan prosedur relaksasi otot progresif, penerapan dan pengamatan (observasi), kemudian hasilnya dicatat dalam lembar observasi. Penerapan teknik relaksasi otot progresif pada pasien DM tipe 2 yang disertai pemberian injeksi insulin terbukti bisa mengurangi kadar gula didalam darah. Penerapan teknik relaksasi otot progresif dapat dijadikan intervensi untuk mengurangi kadar gula darah pada pasien DM tipe 2.
\end{abstract}

Kata kunci : diabetes mellitus tipe 2, teknik relaksasi otot progresif, kadar gula darah

\begin{abstract}
The prevalence of diabetes that occurred in 2015 was 9.3\% and the cases are likely to continue to increase every year. Type 2 diabetes mellitus is caused by resistance to insulin, namely glucose that fails to enter the body, generally affecting people who are over 30 years old. Progressive muscle relaxation is a therapy that can lower blood sugar levels. The purpose of this community service activity is to find out the benefits of progressive muscle relaxation techniques on reducing blood sugar levels in type 2 DM patients at Grandmed Lubuk Pakam Hospital. The method used in this community service is lecture and application, by providing counseling to type 2 DM patients and making observations after completing the counseling. The application of muscle relaxation techniques was carried out on 10 people with type 2 DM. The community
\end{abstract}


Received: 18 June 2021 :: Accepted: 25 June 2021 :: Published: 30 June 2021

service procedure started from an explanation of progressive muscle relaxation techniques and procedures, implementation and observation, then the results were recorded in an observation sheet. The application of progressive muscle relaxation techniques in type 2 DM patients accompanied by insulin injection has been shown to reduce blood sugar levels. The application of progressive muscle relaxation techniques can be used as an intervention to reduce blood sugar levels in type 2 DM patients.

Keywords: type 2 diabetes mellitus, progressive muscle relaxation therapy, blood sugar levels.

\section{Pendahuluan}

Relaksasi otot progresif ialah sebuah tindakan yang bisa mengurangi kadar gula di dalam darah khususnya pasien Diabetes Mellitus, hal ini terjadi akibat mekanisme penekanan saat mengeluarkan hormon yang memicu terjadinya peningkatan kadar glukosa dalam darah, yaitu epinefrin, kortisol, glukagon, adrenocorticotropic hormone (ACHT), kortikosteroid, dan tiroid. Sistem Syaraf simpatis mulai bekerja saat seseorang merasakan nyaman serta tenang. Pada waktu merasakan nyaman dan tenang sistem saraf simpatis akan mempengaruhi hipotalamus dalam menurunkan pengeluaran Corticotropin-Realising Hormon (CRH). Pengeluaran yang berkurang dari $\mathrm{CRH}$ akan berpengaruh terhadap adenohipofisis dalam mengurangi keluarnya hormon adrenocorticotropic (ACHT), yang mengalir dari saluran peredaran darah menuju korteks adrenal. Kondisi ini dapat menghalangi korteks adrenal dalam melepaskan hormon kortisol. Relaksasi otot progresif bisa diterapkan kepada siapapun tanpa melihat keadaan dan situasi khusus terhadap pasien DM (Guyton \& Hall, 2008, dan Setyohadi \& Kushariyadi, 2011).

Internasional Diabetes Federation (IDF) tahun 2015 menjelaskan bahwa dari 177 juta orang di dunia yang mengalami sakit DM tipe 2 dan diperkirakan 25 tahun kemudian akan bertambah sebanyak 300 juta orang. Kasus penyakit diabetes tipe 2 pada tahun 2016 yang menimpa masyarakat di Amerika Serikat yang berumur lebih dari 65 sebanyak 10,9 juta orang $(26,9 \%)$, sedang di Indonesia jumlah pasien yang menderita DM tipe 2 mengalami kenaikan, dari $8,4 \%$ juta jiwa pada tahun 2017 dan diperkirakan naik menjadi $21,3 \%$ juta jiwa pada tahun 2022. Jumlah pasien yang mengalami sakit Diabetes Mellitus di Indonesia sangat banyak, sehingga Indonesia berada pada posisi keempat di dunia setelah negara lain seperti; Amerika Serikat, India, dan China (Wild, 2018 dan Sudoyo, 2006).

Di Sumatera Utara khususnya RSUP H. Adam Malik Medan dari pengelompokan jenis penyakit serta berbagai macam tingkatan usia, jumlah penderita penyakit DM menduduki posisi nomor urut kedua setelah penyakit neoplasma yang sangat berbahaya. Sementara itu dari data kematian pasien berdasar jenis penyakitnya, penyakit Diabetes Mellitus menduduki posisi ke 16 dibandingkan dengan penyakit lainnya. (Dinkes SUMUT,2009).

Hasil dari studi awal pada tanggal 04 November 2018 dari data rekam medis RS.GRANDMED Lubuk Pakam, pasien yang menderita penyakit dalam mulai bulan Januari 2018 - Desember 2018 yang dirawat berjumlah 20.506 orang. Diantara pasien dengan penyakit dalam tersebut, ditemukan pasien yang mengalami gangguan sistem endokrin "DM Tipe 2 " berjumlah 568 orang, jumlah prevalensi sebesar $2,77 \%$ terdiri atas laki-laki sejumlah $328(57,8 \%)$ orang dan perempuan $240 \quad(42,2 \%)$ orang. Tindakan pengobatan yang diberikan untuk mengurangi kadar gula di dalam darah pasien DM Tipe 2 di RS. GRANDMED Lubuk Pakam masih menggunakan terapi farmakologi, seperti memberikan 
Received: 18 June 2021 :: Accepted: 25 June 2021 :: Published: 30 June 2021

injeksi Insulin dengan tujuan mengatur kadar gula di dalam darah pasien dan pemberian obat dengan jenis oral seperti Metformin. Tujuan dari penyuluhan teknik relaksasi otot progresif ini yaitu menurunkan kadar gula di dalam darah pasien DM tipe 2 di RS.GranMed Lubuk Pakam.

\section{Metode}

Metode yang dipergunakan pada kegiatan pengabdian terhadap masyarakat ini yaitu ceramah dan aplikasi, dengan cara memberikan penyuluhan kepada pasien DM tipe 2 dan melakukan observasi setelah selesai melakukan penyuluhan.

Bahan yang dipergunakan pada pengabdian masyarakat ini yaitu materi tentang teknik relaksasi otot progresif. Prosedur pelaksanaan pada pengabdian masyarakat ini dimulai dari memberikan penjelasan tentang teknik relaksasi dan cara melakukannya kepada pasien. Adapun tahapannya menurut Setyoadi (2011) adalah sebagai berikut :

i. Meminta pasien untuk mengendurkan pakaian dan ikat pinggang,

ii. Meminta pasien untuk memejamkan mata,

iii. Meminta pasien untuk menarik nafas yang dalam dan mengeluarkannya,

iv. Meminta pasien untuk mengerutkan dahi, membukamenutup mata, membuka mulut dengan lebar, menjulurkan lidah ke langit-langit mulut, mengunci rahang dengan kuat, bibir dicondongkan kedepan dan bertahan selama 5 detik, kemudian keluarkan nafas secara perlahan dan kendurkan secara perlahan,

v. Meminta pasien untuk menekan kepala kebelakang, anggukkan kepala ke arah dada,

vi. Meminta pasien untuk memutar kepala ke arah bahu kanan dan putar kepala ke arah bahu kiri,

vii. Mengangkat kedua bahu seolah ingin menyentuh telinga secara bersamaan, angkat bahu sebelah kanan seolah ingin menyentuh telinga, angkat bahu sebelah kiri seolah ingin menyentuh telinga,

viii. Menahan lengan dan menggenggam tangan, setelah itu bengkokkan lengan pada siku, kencangkan lengan sambil tetap menggenggam tangan, tahan selama 5 detik. Buang nafas perlahan,

ix. Tarik nafas dalam-dalam dan kencangkan otot dada dan tahan selama 5 detik, hembuskan dan rilekskan perlahan,

x. Kencangkan perut, tekan keluar dan tarik nafas, tahan selama 5 detik, hembuskan dan rileks perlahan,

xi. Mintalah untuk melengkungkan punggung sambil mengambil nafas dalam-dalam tarik nafas dan tekan perut keluar, tahan selama 5 detik, hembuskan dan rilekskan perlahan,

xii. Mintalah supaya menegangkan pinggang, tumpukan berat tubuh pada tumit kaki di lantai, tegangkan otot kaki yang dibawah lutut, lipat jari kaki ke bagian bawah seakan ingin menyentuh telapak kaki dari kaki, naikkan jari kaki keatas seolah-olah menyentuh lutut, tahan selama 5 detik, hembuskan nafas dan perlahan rileks.

xiii. Setelah itu observasi kadar gula darah pasien, kemudian catat dalam lembar observasi.

\section{Hasil dan Pembahasan} Hasil Tabulasi Univariat

Tabel 1. Hasil Analisa Kadar Gula di Dalam Darah sebelum melakukan

Teknik Relaksasi Otot Progresif di Rumah Sakit Grandmed Lubuk Pakam

\begin{tabular}{|l|c|c|c|c|}
\hline $\begin{array}{c}\text { Kadar } \\
\text { Gula } \\
\text { Darah }\end{array}$ & Mean & $\mathrm{N}$ & $\begin{array}{c}\text { Std. } \\
\text { Deviati } \\
\text { on }\end{array}$ & $\begin{array}{c}\text { Std. } \\
\text { Erro } \\
\mathrm{r} \\
\text { Mea } \\
\mathrm{n}\end{array}$ \\
\hline $\begin{array}{l}\text { Kadar } \\
\text { gula } \\
\text { darah } \\
\text { sebelum } \\
\text { melakuk } \\
\text { an teknik } \\
\text { relaksasi }\end{array}$ & $\begin{array}{c}243,9 \\
0\end{array}$ & 0 & 11,210 & 3,54 \\
\end{tabular}


Received: 18 June 2021 :: Accepted: 25 June 2021 :: Published: 30 June 2021

\section{otot
progresif}

Hasil yang diperoleh berdasarkan

Tabel 1. sebelum dilakukannya teknik relaksasi otot progresif yaitu 243,90 dengan nilai SD (standar deviasi) 11,210 dan SE (standar error) 3,54.

Tabel 2. Hasil Analisa Kadar Gula di Dalam Darah sesudah melakukan Teknik Relaksasi Otot Progresif di Rumah Sakit Grandmed Lubuk Pakam

\begin{tabular}{|l|c|c|c|c|}
\hline $\begin{array}{c}\text { Kadar } \\
\text { Gula } \\
\text { Darah }\end{array}$ & Mean & $\mathrm{N}$ & $\begin{array}{c}\text { Std. } \\
\text { Deviati } \\
\text { on }\end{array}$ & $\begin{array}{c}\text { Std. } \\
\text { Erro } \\
\mathrm{r} \\
\text { Mea } \\
\mathrm{n}\end{array}$ \\
\hline $\begin{array}{l}\text { Kadar } \\
\text { gula } \\
\text { darah } \\
\text { sesudah } \\
\text { melakuk } \\
\text { an teknik } \\
\text { relaksasi } \\
\text { otot } \\
\text { progresif }\end{array}$ & $\begin{array}{c}200,8 \\
0\end{array}$ & 0 & 31,407 & 9,93 \\
2
\end{tabular}

Hasil yang diperoleh berdasarkan

Tabel 2. menunjukkan bahwa rerata kadar gula di dalam darah sesudah melakukan teknik relaksasi otot progresif yaitu sejumlah 200,80, dengan SD (standar deviasi) 31,407 danSE (standar error) 9,932.

\section{Hasil Tabulasi Bivariat}

Tabel 3. Hasil Analisa Kadar Gula di Dalam Darah Sebelum dan Sesudah melakukan Teknik Relaksasi Otot Progresif di Rumah Sakit Grandmed Lubuk Pakam

\begin{tabular}{|c|c|c|c|c|c|}
\hline $\begin{array}{c}\text { Kad } \\
\text { ar } \\
\text { Gula } \\
\text { Dara } \\
\text { h }\end{array}$ & $\mathrm{N}$ & $\begin{array}{c}\text { Mea } \\
n\end{array}$ & $\begin{array}{c}\text { Std. } \\
\text { Devi } \\
\text { atio } \\
\text { n }\end{array}$ & $\begin{array}{c}\text { Std. } \\
\text { Erro } \\
r \\
(\mathrm{SE})\end{array}$ & $\begin{array}{c}p- \\
\text { Value }\end{array}$ \\
\hline $\begin{array}{l}\text { Seb } \\
\text { elu } \\
\text { m } \\
\text { dan } \\
\text { sesu } \\
\text { dah }\end{array}$ & $\begin{array}{l}1 \\
0\end{array}$ & $\begin{array}{c}43,1 \\
00\end{array}$ & $\begin{array}{c}27,7 \\
95\end{array}$ & $\begin{array}{c}8,78 \\
9\end{array}$ & 0,001 \\
\hline
\end{tabular}
rerata kadar gula di dalam darah pada penderita DM tipe 2 sebelum dan sesudah melakukan teknik relaksasi otot progresif yaitu 43,100 dengan SD (standar deviasi) sebesar 27,795 dan SE (standar error) sebesar 8,789. Hasil uji statistik menunjukkan hasil nilai $\mathrm{p}=$ $0,001 \leq a=0,05$. Sehingga dapat disimpulkan bahwa teknik relaksasi otot progresif mampu menurunkan kadar gula di dalam darah pada penderita DM tipe 2 di rumah sakit Grandmed Lubuk Pakam.

\section{Pembahasan}

Berdasarkan

pengabdian masyarakat yang dilakukan, dimana nilai rerata kadar gula pasien DM tipe 2 sebelum melakukan teknik relaksasi otot progresif adalah 243,90. Setelah melakukan teknik relaksasi otot progresif, rerata kadar gula pasien DM tipe 2 adalah 200,80.

DM tipe 2 merupakan penyakit kronik yang menyebabkan kelainan metabolisme tubuh manusia dengan komplikasi makrovaskuler dan neurologis, menurut penelitian yang dilakukan Widianingsih menyebutkan jika teknik relaksasi otot progresif dilakukan terhadap pasien DM tipe 2, maka kadar gula di dalam darah dapat turun dengan cepat. Teknik relaksasi otot progresif dilakukan oleh pasien dengan cara menarik napas dalam (Damayanti Santi, 2015, dan Putri \& Widaningsih, 2017).

\section{Kesimpulan}

Kadar gula di dalam darah pada pasien DM tipe 2 yang hanya menggunakan terapi injeksi insulin (tanpa menerapkan teknik relaksasi otot progresif) diperoleh hasil rataratanya sebesar 244 mg/dl. Sedangkan setelah menerapkan teknik relaksasi otot dan disertai pemberian insulin, maka nilai rerata kadar gula di dalam darah pasien DM tipe 2 menjadi 201 $\mathrm{mg} / \mathrm{dl}$. Hal ini menunjukkan bahwa terapi insulin yang disertai dengan penerapan teknik relaksasi otot progresif dapat mengurangi kadar gula dalam darah pasien DM tipe 2 .

Berdasarkan hasil yang diperoleh, diharapkan penerapan dari teknik 
Received: 18 June 2021 :: Accepted: 25 June 2021 :: Published: 30 June 2021

relaksasi otot progresif bisa dijadikan intervensi untuk menurunkan kadar gula di dalam darah pada pasien DM tipe 2.

\section{Ucapan Terima Kasih}

Terima kasih penulis sampaikan kepada Institut Kesehatan Medistra Lubuk Pakam yang telah bersedia mendanai kegiatan Pengabdian Masyarakat yang dilakukan oleh penulis, dan kepada seluruh responden (pasien diabetes mellitus tipe 2) Rumah Sakit Grandmed Lubuk Pakam yang telah bersedia membantu peneliti dalam kegiatan Pengabdian Masyarakat ini.

\section{Daftar Pustaka}

Damayanti, Santi. 2015. Diabetes Mellitus dan Penatalaksanaan Keperawatan. Nuha Medika, Yogyakarta

DinkesSUMUT,2009.DataPenelitian:http ://rsupadammalik.blogspot.co.id/ 2013/06/data-penelitiandiabetes-mellitus.html

Guyton, A.C \& Hall, J.E. 2008. Buku Ajar Fisiologi Kedokteran. Edisi. 11. Jakarta : EGC

International Diabetes Federation.2015. WDD 2015 Campaign. Sara Webber: International Diabetes Federation.

Kustanti, E., \& Widodo, A. (2008). Pengaruh Teknik Relaksasi Terhadap Perubahan Status Mental Klien Skizofrenia Di Rumah Sakit Jiwa Daerah Surakarta. Berita Ilmu Keperawatan ISSN 1979-2697, Vol. 1 No.3, September 2008 : 131-136

Putri, H.D., Widaningsih. 2017. Relaksasi Otot Progresif terhadap Penurunan Kadar Gula Darah pada Pasien Diabetes Mellitus Tipe 2. Indonesian Journal of Nursing Health Science

Setyohadi dan Kushariyadi. 2011. Terapi Modalitas pada Klien Psikogeriatrik. Salemba Medika, Jakarta

Sudoyo, A.W., Setiyohadi,B., Alwi, I., \& Setiati, S. 2006. Buku Ajar Ilmu Penyakit Dalam. (edisi 3).
Jakarta: Pusat Penerbit Departeman Penyakit Dalam FKUI Wild et al., 2018. Report of the Expert Committee on the Diagnosis and Classification of Diabetes Mellitus. Diabetes Care: http://www.diabetes mellitus. com/ 2018 